\title{
Territórios do cuidar: comunicação e memória nas medicinas dos povos tradicionais afro-brasileiros
}

\author{
Health care territories: communication and memory in the practice of \\ medicine by traditional Afro-Brazilian people
}

\section{Territorios del cuidar: comunicación y memoria de la medicina de los pueblos tradicionales afro-brasileños}

\author{
Adriana de Holanda Cavalcanti ${ }^{1, a}$ \\ adriana.edugrio@gmail.com | https://orcid.org/oooo-0003-4164-7401 \\ ${ }^{1}$ Fundação Oswaldo Cruz, Escola Nacional de Saúde Pública. Rio de Janeiro, RJ, Brasil. \\ a Mestrado em Psicologia pela Universidade Federal Fluminense.
}

\section{RESUMO}

O presente artigo aborda a cultura e a medicina dos povos tradicionais afro-brasileiros como determinantes sociais da saúde em diferentes grupos étnicos, suas relações existentes com processos comunicativos e a efetivação de políticas públicas, especialmente a denominada Política Nacional de Práticas Integrativas em Saúde e Complementares no Sistema Único de Saúde, assim como o campo da educação patrimonial em saúde. A partir das análises de narrativas do projeto na área de comunicação e saúde por meio das linguagens das artes, realizado na Fundação Oswaldo Cruz entre 2004 e 2008, em articulação com as questões da tese de doutorado sobre as memórias da diversidade sociocultural dos povos tradicionais em suas artes de cura na Jurema Sagrada, em desenvolvimento na Pós-Graduação em Memória Social da Universidade Federal do Rio de Janeiro, este texto indica pontos importantes acerca dos processos de comunicação na educação em saúde mediante o mapeamento dos territórios do saber como estratégias de memórias e resistências de grupos étnicos.

Palavras-chave: Educação em saúde; Educação patrimonial; Memória; Comunicação; Jurema Sagrada.

\section{ABSTRACT}

This article examines both culture and medicine practice by the traditional Afro-Brazilian people as health social determinants in different ethnic groups, their relations with communicative processes and the implementation of public policies, specially the Política Nacional de Práticas Integrativas em Saúde e 
Complementares no SUS (National policy of integrative and complementary health practice by SUS), and the field of heritage of health education. It is based on the narrative analysis of the project developed by Fundação Oswaldo Cruz (Fiocruz) from 2004 to 2008 in the communication and health area by means of art languages, related to issues proposed on $\mathrm{PhD}$ thesis about memories of the cultural and social diversity revealed by traditional people in its cure arts in Jurema Sagrada, in phase of development through the Programa de Pós-Graduação em Memória Social (Postgraduate program in social memory at Unirio Universidade Federal do Rio de Janeiro. This text points out important issues about communication processes in health education through mapping of knowledge territories as strategies for memory and resistance of ethnic groups.

Keywords: Health education; Heritage of health education; Memory; Communication; Jurema Sagrada.

\section{RESUMEN}

Este artículo analiza la cultura y la medicina de los pueblos tradicionales afro-brasileños como determinantes sociales de la salud en diferentes grupos étnicos, sus relaciones existentes con procesos comunicativos y la implementación de políticas públicas, especialmente la Política Nacional de Práticas Integrativas em Saúde e Complementares no SUS (Política nacional de prácticas integrales y complentarias de salud en el SUS) y el campo de la educación patrimonial de la salud. Él se basa en el análisis de narrativas del proyecto en comunicación y salud a través de los lenguajes de las artes, realizado en la Fundação Oswaldo Cruz (Fiocruz) en el periodo de 2004 hasta 2008, relacionado con las cuestiones de tesis doctoral sobre las memorias de la diversidad sociocultural de pueblos tradicionales revelada en sus artes curativas en Jurema Sagrada, en desarrollo en el Programa de Pós-Graduação em Memória Social (Programa de posgrado en memoria social) de la Universidade Federal do Rio de Janeiro (Unirio). El presente texto apunta cuestiones importantes sobre los procesos de comunicación en la educación en salud a través de la esquematización de los territorios del saber como estrategias de memorias e resistencia de los grupos étnicos.

Palabras clave: Educación en salud; Educación patrimonial; Memoria; Comunicación; Jurema Sagrada.

Contribuição dos autores:

Concepção e desenho do estudo: Adriana de Holanda Cavalcanti.

Aquisição, análise ou interpretação dos dados: Adriana de Holanda Cavalcanti.

Redação do manuscrito: Adriana de Holanda Cavalcanti.

Revisão crítica do conteúdo intelectual: Leon Lucius de Holanda Continentino, Javier Lifschtz.

Declaração de conflito de interesses: não há.

Fontes de financiamento: não houve.

Considerações éticas: não há.

Agradecimentos/Contribuições adicionais: Maria da Soledade (in memoriam).

Histórico do artigo: submetido: 26 jun. 2019 | aceito: 02 jun. 2020 | publicado: 30 set. 2020.

Apresentação anterior: não houve.

Licença CC BY-NC atribuição não comercial. Com essa licença é permitido acessar, baixar (download), copiar, imprimir, compartilhar, reutilizar e distribuir os artigos, desde que para uso não comercial e com a citação da fonte, conferindo os devidos créditos de autoria e menção à Reciis. Nesses casos, nenhuma permissão é necessária por parte dos autores ou dos editores. 


\section{INTRODUÇÃO}

O presente artigo aborda a temática da relação entre a memória narrativa das medicinas dos povos tradicionais afro-brasileiros e a construção de processos de comunicação destinados à educação em saúde. Para tanto, compartilhamos aqui algumas reflexões da pesquisa em desenvolvimento junto ao curso de Pós-Graduação em Memória Social da Universidade Federal do Rio de Janeiro (Unirio)i.

$\mathrm{Na}$ construção da tese, pesquisamos a importância das narrativas dos povos tradicionais como dispositivos de comunicação acerca de suas memórias de cuidados em saúde. As questões que norteiam esse estudo são: Como as narrativas estabelecem elos de memória e de comunicação dos saberes nas medicinas tradicionais? E como essas narrativas de memórias das medicinas tradicionais dialogam com as medicinas acadêmicas contemporâneas?

Elegemos, em nosso recorte de pesquisa, estabelecer uma análise de narrativas dos grupos envolvidos com as comunidades-terreiro da Jurema Sagrada, tanto em seus rituais espirituais como em seus processos de cura através das manifestações culturais. Na comunidade-terreiro, elegemos especialmente as narrativas fundadoras do Projeto Griôii , intitulado 'Arte e Magia na Jurema Pernambucana', realizado por meio da Ação Griô Nacional, do Ministério da Cultura (MinC). Por narrativas fundadoras nomeamos, aqui, as histórias transmitidas pela matriarca do terreiro de Jurema Sagrada em Pernambuco, a Juremeira Maria da Soledade (in memoriam) e por todos os membros da comunidade envolvidos no Projeto Griô. Das vivências e oficinas realizadas nesse período, nasceu o projeto de construção da 'Escola de Cultura e Saúde Semente de Jurema', um projeto de 'Escola Sem Muros', onde a educação em saúde se faz através das artes e culturas tradicionais em diálogo com os saberes acadêmicos contemporâneos.

Além das narrativas fundadoras da Escola de Cultura e Saúde Semente de Jurema, também agregamos, em nossas reflexões e análises, as narrativas oriundas da cosmovisão geral dos povos tradicionais afrobrasileiros e afro-asiáticos, mas tomando como base o estudo da relação entre medicina e espiritualidade na ciência da Jurema Sagrada: uma tradição de cura espiritual de matriz indígena, xamânica, originalmente brasileira, que se faz através do culto a uma árvore, nomeada popularmente Jurema, cujo nome científico é mimosa hostilis, da família das Acácias, planta sagrada para diversos povos tradicionais no mundo.

Portanto, estamos trabalhando com três 'grupos de narrativas': os juremeiros e membros das comunidades tradicionais de Jurema; os participantes de vivências e oficinas do projeto 'Arte e Magia na Jurema Pernambucana'/Escola Semente de Jurema; e as narrativas oriundas das literaturas escritas e orais, além de documentos de memória científicos e artísticos acerca dos povos tradicionais da Jurema sagrada.

Neste artigo, vamos nos concentrar em apresentar algumas reflexões conceituais acerca da cosmovisão dos povos tradicionais, a partir da perspectiva da Jurema Sagrada e de suas medicinas; explicitaremos como os processos de comunicação, através de narrativas orais, são meios de transmissão e preservação de suas memórias de cura, de suas epistemologias específicas e de seus processos pedagógicos. São pontos conceituais que ligam de forma transversal a comunicação comunitária, a educação em saúde e as medicinais tradicionais.

Nossa metodologia propõe uma revisão crítica, epistemológica, filosófica e reflexiva sobre a importância das cosmovisões dos povos tradicionais de matriz africana e indígena, transmitidas pelos mestres de cura que as guardam e protegem. Visitando a história da produção discursiva da memória apresentada pelos livros didáticos e pelas práticas pedagógicas no Brasil, desde a formação das primeiras escolas do colonizador europeu, vemos a produção maciça do esquecimento dos povos indígenas e africanos dos seus saberes e fazeres na saúde e nos processos e materiais de comunicação do Sistema Único de Saúde (SUS).

ii O Projeto Griô 'Arte e Magia na Jurema pernambucana' foi realizado entre 2010 e 2013, apoiado pelo Ministério da Cultura/ Programa Cultura Viva. Para mais informações sobre o projeto, acessar: http://escolasementedejurema.wordpress.com. 
Por dentro desses fluxos de poderes e memórias, a tecedura desta escrita nasce de uma perspectiva de não violência educacional, por meio da Pedagogia Griôiii aplicada à Educação em Saúde. Em 2006, foi sistematizada a 'Ação Griô Nacional' a partir de uma iniciativa pedagógica da organização não-governamental 'Grãos de Luz e Griô' (BA), nomeada Pedagogia Griô, concebida por Lillian Pacheco e Márcio Caires', que favoreceu a formação de um programa de cultura e educação. A Ação Griô Nacional/Rede de Tradição Oraliv $^{\text {, }}$ da qual participamos, nos inspirou a conceber a formação da Escola de Cultura e Saúde Semente de Jurema como uma escola de memórias, artes e ofícios tradicionais em cultura e saúde.

É a partir dessa experiência pedagógica que investigamos a relação entre a comunicação como dispositivo de memória acerca das comunidades tradicionais de Jurema que, em suas artes medicinais, sua música, seus saberes e sua ciência, colorem de saúde coletiva as neocomunidades e comunidades ${ }^{3}$ urbanas de diversas cidades nos estados como Pernambuco, Paraíba, Rio de Janeiro e São Paulo.

\section{DESENVOLVIMENTO DO TRABALHO}

\section{Narrativas das culturas tradicionais: comunicação, memória e saúde}

Este primeiro ponto de reflexão versa sobre a importância do método do narrador (ou do contador de histórias). Este método vem sendo validado ao longo de nosso percurso acadêmico, tanto na pesquisa como na gestão em saúde. O projeto 'Processos de Comunicação em Saúde Pública: Linguagens da Arte e Humanização do SUS' que esteve sob nossa coordenação na Fundação Oswaldo Cruz (Fiocruz), foi o primeiro a inserir a linguagem da capoeira e outras culturas tradicionais afro-brasileiras na dinâmica do cuidado hospitalar, com foco em dinamizar grupos de comunicação em saúde, na perspectiva da Política Nacional de Humanização do SUS. O objetivo era promover o deslocamento do lugar discursivo de cada participante, fazendo-os experienciar, através da linguagem corporal e artística, da filosofia, da música e das histórias cantadas da capoeira, outros modos de percepção acerca dos processos de comunicação padronizados em uma assistência desumanizada, tecnicista e não integrativa.

A experiência deste projeto destacou que a vivência da diversidade cultural na formação dos profissionais de saúde é de suma importância para impactar as relações de comunicação nos processos saúde e doença, na elaboração de materiais informativos acerca de tratamentos e modos de prevenção de determinadas patologias que atingem as populações mais vulneráveis em nosso país, ou seja, as negras e indígenas. Deste projeto, realizado no hospital do Instituto Nacional de Infectologia Evandro Chagas (INI) da Fiocruz, pudemos elencar uma série de propostas metodológicas para a inserção sistemática da sabedoria dos povos tradicionais nos processos de comunicação estabelecidos na dinâmica hospitalar. O campo da Gestão da

iii Griô é uma forma abrasileirada da palavra francesa griot (masculino) ou griotte (feminina), que traduz djeli do dialeto banaman bambaara e significa o sangue (a vida que circula), a biblioteca viva de uma comunidade, a transmissão oral da sabedoria ancestral de geração em geração. Segundo Lillian Pacheco e Marcio Caires², as origens dos griots se localiza no sul do Saara, noroeste da África, na tradição oral dos grupos étnicos Bambaaras e Fulas, na Região do Mali - África. Os griots são responsáveis por uma sabedoria e uma arte verbal presentes nos rituais da vida social: nascimento, iniciação, aliança matrimonial, cerimônia de casamento e funeral. Os griots têm uma linhagem (casta social e política), além de um lugar social e econômico determinante no funcionamento das sociedades do noroeste da África. Os princípios e práticas da pedagogia griô são baseados em favorecer a ligação entre o ser e a palavra; a responsabilidade entre o ser e a terra; o desenvolvimento da memória; a importância do conhecimento integral e integrado; os rituais de vínculos afetivos na educação; a vivência da rede de transmissão oral; a valorização das artes e dos ofícios de tradição; o lugar político-social dos mestres e griôs; a convivência intergeracional; as histórias de vida como fonte do conhecimento; e o saber e a palavra como autoria da cadeia ancestral de transmissão oral.

iv A Ação Griô Nacional nasceu como projeto criado e proposto pelo Ponto de Cultura Grãos de Luz e Griô, da Bahia, para o programa Cultura Viva da Secretaria de Cidadania Cultural do Ministério da Cultura. A Ação Griô é uma rede que envolve 130 projetos pedagógicos de diálogo entre a tradição oral e a educação formal, mais de 750 griôs e mestres bolsistas de tradição oral do Brasil, 600 escolas, universidades e outras entidades de educação e cultura e 100 mil estudantes de escolas públicas. Em 2012, a Ação Griô iniciou a execução do projeto de implementação da Universidade Griô, que concluiu o convênio em 2013 com cinco universidades públicas para realização de Cursos de Extensão e Pós-Graduação na Pedagogia Griô integrados com diversas práticas de diálogo entre tradição oral, educação e cultura digital. 
Pesquisa e Ensino em Comunicação e Saúde revela que essa diferenciação entre usuários e profissionais de saúde apresenta questões relativas à diversidade de culturas e linguagens, que muitas vezes é tida como conflituosa e negativa para a adesão ao tratamento dos pacientes, marcada pela linguagem técnica e racionalista da medicina ocidental modernav . A realização deste projeto foi de suma importância para a memória institucional da Fiocruz no que tange à relação estabelecida entre a medicina popular, oriunda dos discursos dos povos tradicionais, e a medicina moderna, de matriz epistemológica europeia, que marca os processos de formação profissional em saúde.

Após esta experiência no espaço hospitalar, pudemos acessar diretamente a dinâmica de cuidado em saúde dentro de uma comunidade tradicional de Jurema. A partir dessa vivência no território de saber tradicional de matriz indígena, pudemos construir atividades de educação em saúde na perspectiva desta comunidade para, em seguida, analisar as narrativas presentes nos arquivos de memória da construção do projeto Escola Semente de Jurema. As atividades do projeto envolveram mestres das comunidades tradicionais, educadores, pesquisadores, estudantes, profissionais e estudantes da área da saúde, que participaram de oficinas e vivências, realizados em dez anos de atividade do projeto, no Rio de Janeiro e Pernambuco.

De acordo com a literatura científica sobre a tradição Jurema Sagrada, o autor Rodrigo de Azevedo Grunewald $^{4}$, nos fornece indícios de que "desde o período colonial, registra-se no Brasil o uso ritual da jurema entre populações indígenas, além da recorrência de usuários da jurema em meios rurais e urbanos”vi. Porém, o uso ritualístico tradicional da Jurema Sagrada, que é a base da epistemologia da sua medicina tradicional indígena, tem sua ocorrência mais marcante no semiárido do Nordeste brasileirovii.

No entanto, nossos estudos apontam que a bebida feita na Jurema Sagrada não se relaciona com seu uso recreativo ou psicoativo, feito fora dos seus contextos originários. O uso medicinal da Jurema Sagrada somente se verifica dentro dos rituais das comunidades tradicionais ou preparados pelo juremeiro para que chegue até um enfermo ou um paciente que necessite desse cuidado.

A desdobra da sabedoria da ciência da Jurema nos traz outras narrativas além dos índios perseguidos, assassinados e violentados por colonizadores. Traz narrativas de ações de saúde nos quilombos tradicionais e urbanos, suas formas de resistências, de modos de lutar, de acolher e de saberes que floresceram porque ficaram germinados, escondidos nas matas, nas práticas ínfimas de resistência e invenção de jeitos, táticas de estar no mundo, acolhendo irmãos africanos, 'bruxas' oriundas da inquisição e uma série de etnias e saberes, em um tempo-espaço de trocas e compartilhamento entre povos. Não estamos tratando apenas

\footnotetext{
v As questões relativas às racionalidades médicas e a importância da arte como dispositivo de comunicação no espaço hospitalar foram apresentadas no curso de Especialização em Comunicação e Saúde, também realizado na Fiocruz, sob o título 'Boca de cena: arte, discurso e poder na comunicação e saúde'. Todas as nossas produções de pesquisa estão disponíveis no espaço virtual da Escola Semente de Jurema, disponível em: http://escolasementedejurema.wordpress.com, na seção 'Publicações'.

vi Além disso, vários contextos e usos da Jurema podem ser salientados desde os usos pelas populações tradicionais até experimentações contemporâneas realizadas por psiconautas que buscam experimentar seus aspectos místicos e aprimorar receitas a fim de obterem as melhores extrações psicoativas, inclusive para testar novas hipóteses acerca da composição e de ações bioquímicas da jurema em pacientes com dependência química de heroína na Holanda. No entanto, nossos estudos apontam que a Jurema Sagrada das comunidades tradicionais não se relacionam com seu uso recreativo. O uso medicinal da Jurema Sagrada somente se verifica dentro dos rituais das comunidades tradicionais.
}

vii No momento, é importante ressaltar que, em partes dessa planta, mais concentradamente nas entrecascas das raízes, encontram-se largas concentrações do alcalóide N, N-dimetiltriptamina (DMT), que é considerado um alucinógeno pela medicina moderna. Já para seus experimentadores, ela é tida como um enteógeno, tendo em vista sua capacidade de promover experiências místicas. São múltiplas as formas de preparo e de consumo da jurema. Desde os usos indígenas a outros contextos tradicionais, registram-se várias plantas e outros ingredientes que podem eventualmente ser adicionados à jurema para seu uso ritual. De fato, só a partir de 1938, com a Missão de Pesquisas Folclóricas, levada a efeito por iniciativa de Mario de Andrade, é quando o toré, performance mais corriqueira entre os indígenas do interior do Nordeste, vai começar (no caso acima entre os Pankararu) a ser sistematicamente registrado. 
de exclusão e afirmação identitárias, mas de sistemas de generosidade e acolhimento, reconhecimento e preservação das sabedorias de povos antigos ${ }^{\text {viii. }}$

A construção participativa de processos de comunicação comunitária, na perspectiva complementar e integrativa da saúde, especialmente no que concerne aos territórios de saber tradicionais, possibilitam a criação de práticas de memória frente à política de esquecimento social que veio demarcando a exclusão de construção de políticas públicas de educação em saúde que contemplem, valorizem e disseminem as medicinas desses povos.

\section{Medicina e espiritualidade: comunicação em territórios do cuidar}

Nos espaços de cuidados de saúde da Jurema Sagrada, são através das narrativas de memórias que o xamã, o pajé ou zelador espiritual se constituem como protagonistas das ciências de cura tradicionais. O juremeiro, como elo vivo na cadeia de transmissibilidade das sabedorias e da forma de zelar pelas medicinas herdadas de seus ancestrais, é considerado o protagonista dessas memórias de saúde, feitas em uma comunicação em rede. O zelador de Jurema, ao cuidar do culto aos mortos ('os antepassados'), recebe ensinamentos para os vivos, sobre a saúde e a doença. Portanto, há um elo sagrado de comunicação entre memória e morte, vida e esquecimento e saúde e doença como polaridades complementares de um sistema único.

Para adentrarmos a episteme da ciência da Jurema, cabe destacar que a ideia sagrada fundamentalmente dos indígenas brasileiros é, sem dúvida, o culto aos seus mortos. Esta crença, a mais sagrada e tradicional, insinua-se em todos os atos da vida social das distintas nações indígenas do Brasil. Os aprendizados acerca da dinâmica da vida e da morte, da saúde e da doença, dentro das comunidades tradicionais afrobrasileiras, é fundamental para a compreensão de uma medicina integrativa, que contemple o saber dos povos originários, tradicionais.

As narrativas que aparecem nas vivências e atividades da Escola Semente de Jurema invocam os participantes ao deslocamento dos seus modos delembrar e esquecer, de seus lugares discursivos demarcados por uma ótica separatista, individualista, e contemplam uma experimentação coletiva e abrangente acerca do autoconhecimento como processo terapêutico, como cuidado de si e de sua comunidade; de sua conexão com os elementos da natureza como processo de cura e de entendimento de um sistema epistemológico sobre a morte e o adoecer como aprendizados para o bem viver e vice-versa. É um sistema epistemológico que valoriza o bem-estar físico, mental e espiritual como chaves de conhecimento para uma 'boa morte' - os povos tradicionais contemplam que a morte é uma vivência marcada pelo renascimento da alma, liberta do invólucro material que é o corpo físico.

Cabe destacar que nessas vivencias com a sabedoria da Jurema, os materiais de comunicação que termos produzido em videoaulas, por exemplo, servem como esse dispositivo de memórias da saúde, que se afinam, segundo Araújo e Cardoso5, com o princípio de integralidade do SUS: "tem atributos da integralidade semelhantes aos que consideramos indispensáveis para uma boa comunicação: práticas de escuta e reconhecimento do outro (polifonia), serviços como espaço de conversas e trocas (de comunicação) e recusa ao fechamento dos sentidos e ao privilegiamento das falas autorizadas. Uma outra dimensão da integralidade é sua oposição aos especialismos (e) normalmente a comunicação é delegada ao especialista. O princípio da integralidade permite perceber um processo

\footnotetext{
viii A comunidade tradicional de Jurema se funda na Paraíba e em Pernambuco, e tem, na Pajelança indígena, no Toré e no culto à árvore da Jurema e seus poderes de cura, enteógenos, suas principais características. Com a chegada dos irmãos africanos, especialmente de etnia Bantu, os índios acolhem tanto a cosmologia como a linguagem e passam a fundir-se em rituais de encantamento dos saberes desses povos, o que lhes permitiu fundar o Quilombo dos Malungos, entre Pernambuco e Paraíba, no Nordeste brasileiro. Atualmente, tem adeptos no Rio de Janeiro, São Paulo, Minas Gerais, Goiás e Portugal. A Jurema Sagrada é guardiã espiritual do Maracatu de Nação, Maracatu Rural, Sambada de Coco, Cavalo Marinho, Ciranda, Coco de Toré, Caboclinho, entre outras várias brincadeiras populares do Nordeste.
} 
que contempla a formação dos sentidos sociais na sua inteireza, permite compreender a comunicação como espaço de produção social dos sentidos”.

A integralidade do SUS também se conecta coma perspectiva de saúde integral que versa sobre o bemestar físico, mental e social, segundo a Organização Mundial da Saúde (OMS). Segundo Borges ${ }^{6}$, "Alguns outros grupos consideram que esse bem-estar social seja também espiritual e ecológico. Assim, a saúde pode ser definida como bem-estar biopsicossocial-espiritual-ecológico, ou seja: bem-estar físico, psicológico (mental e emocional), social, espiritual (sentido para a vida) e ecológico (ambiental)".

Portanto, a ausência de sintomas de desequilíbrio no funcionamento do corpo físico não é o foco do sistema de saúde integrativo das comunidades tradicionais e nem da OMS, mas sim a construção de um processo permanente de relação entre o bem-estar físico, mental e espiritual, de uma relação produtora de vida plena, potente. Esse cuidado integrativo, que engloba a alimentação, o uso sustentável da água, do solo, dos vegetais e minerais, entre outros elementos, necessariamente nos convoca a perceber outros fluxos de comunicação na relação saúde e doença. Ousar criar e gerir um sistema de comunicação em saúde integrativa é um ensinamento que essas comunidades tradicionais com epistemologias rizomáticas nos convidam a aprendermos.

Através dos estudos de Reginaldo Prandi7, podemos observar que "para o índio, o fumo é a planta sagrada e é a sua fumaça que cura as doenças, põe o pagé em comunicação com os espíritos de cura da natureza”. O autor destaca, portanto, que tratar os doentes é o dever mais comum dos pajés e o uso do tabaco é sempre prelúdio e complemento necessário dessa operação. E esta é uma operação de comunicação, uma narrativa de partilha de saberes para a boa saúde, para a cura, para cuidar. Assim, a força da Jurema não é apenas uma força material, do sumo da planta, e sim uma força espiritual. A árvore é concebida como encarnação da verdadeira ciência. A iniciação nesta comunidade tradicional torna-se uma iniciação vegetal. Assim, a Jurema Sagrada não se resume a uma bebida enteógena, ela é uma ciência, uma sabedoria que compreende um complexo rizomático, de saberes de povos antigos que dialogam entre o portal dos vivos e dos mortos, da memória e do esquecimento.

Neste sentido, seguindo a proposta de Mircea Eliade ${ }^{8}$, articulamos a Jurema com o arquétipo da "árvore cósmica" ou "árvore da vida”, que vincula o homem com suas verdades místicas. Este conhecimento espiritual é investido de seus mecanismos específicos de comunicação, que não se restringem à relação unívoca entre um emissor e um receptor.

Por conceberem que todo adoecer repousa sobre o desequilíbrio espiritual que se materializa no corpo físico, a relação entre saúde e espiritualidade é extremamente relevante para a medicina dos povos tradicionais; não havendo separação entre corpo-mente-espírito, mas sim dimensões da vida humana e do meio ambiente que coexistem e, portanto, devem ser cuidadas de forma integrativa, narradas por teias que enredam estas três esferas da saúde. Os povos tradicionais nos ensinam como se pratica uma medicina integrativa e uma forma de comunicação própria desta visão de saúde.

\section{COMUNICAÇÃO E MEMÓRIAS NARRATIVAS DA JUREMA SAGRADA}

Oliveira9 ${ }^{9}$ se aprofunda no que considera a "dimensão fundamental dos cânticos (música): arte da palavra cantada que é concebida em sua experiência mística e seu conteúdo espiritual”. Dessa forma, os textos de tradição oral podem prover mais do que formas de representação ou imaginário coletivo; eles podem ser vistos como "expansões da consciência dos indivíduos" ${ }^{\circ}$. Portanto, as músicas nas comunidades de Jurema Sagrada são histórias de memórias cantadas e servem de base comunicacional para todos os envolvidos em seus rituais de cura.

A música, portanto, é um dos elementos fundamentais para o protagonismo dos mestres de territórios medicinais sagrados de matriz indígena e africana, elo de escuta da voz ancestral, que deve ser contemplado 
nas construções de peças e sistemas de comunicação para a educação em saúde. A música para o povo indígena é ao mesmo tempo rito e mito, cura e magia, alegria e memória; é o rito de comunicação com a ancestralidade no balançar do maracá, na dança do toré. É o ritmo que dá forma ao rito, é o cântico que desperta o poder de cura dos guardiões sagrados das folhas, das ervas medicinais. É através do cântico que a comunicação se estabelece entre o divino e o profano, entre a saúde e a doença, entre o sagrado segredo e a magia da materialização da cura.

Portanto, a noção de saúde integral presente nas medicinas dos povos tradicionais converge para uma comunicação ritual porque contempla as comunicações espirituais, uma evocação de linguagens heterogêneas, em que som e silêncio são pontos sagrados e códigos de interação entre os diversos planos a serem cuidados. Logo, não se trata de um sistema informativo, mas dialógico, reflexivo, contemplativo e meditativo, em que o som é criador de vibrações de cura e transformação energética.

Ainda no texto "Jumerologia" podem-se identificar e sistematizar nove aspectos relevantes para entendermos a complexidade das medicinas tradicionais da Jurema Sagrada: 1) a Jurema como espaço mítico sagrado, a árvore sagrada e bebida medicinal, como sustentação mística e material teológica principal; 2) a ciência da Jurema como elemento chave de ligação fundamental entre o princípio masculino/feminino, a teofania e hierofania no seu cosmo, o diálogo do sagrado com o material através das diversas divindades; 3) os (as) juremeiros (as), zeladores de Jurema, como veículos de comunicação entre o espiritual e o material, os que fazem o ritual sagrado existir de fato e os que perpetuam a tradição (elos de memória e comunicação); 4) as ervas e seus poderes místicos de cura holística como matérias do uso litúrgico na Jurema; 5) a fumaça dos cachimbos como elemento de comunicação e manipulação da força da ciência da Jurema, a ciência alquímica e mágica; 6) a filosofia dos cânticos que são a base sagrada da ética e orientação teológica, social e comportamental geral dos juremeiros; 7) a comunidade, a aliança entre os terreiros de Jurema, que juntos formam a grande 'cidade' de força e troca de saberes que se retroalimentam umas às outras; 8) o corpo do rito ritmo, dança e cânticos, invocações rezas e orações (tradição oral), que dão dinâmica e sustentação para a prática cultural ao corpo e ao imaginário dos juremeiros; 9) a vida e a alegria como celebração de si (cuidado de si) e do Universo.

Por seu princípio agregador, o terreiro de Jurema, como local onde esses saberes convergem, conversam, onde compartilham-se aprendizados e espaços de cura com a matriz indígena, também acolhe a medicina contemporânea: por exemplo, nas campanhas de vacinação e prevenção de doenças sexualmente transmissíveis, esses espaços são utilizados pelas equipes de saúde do SUS para chegar até a população. A zeladora Maria da Soledade sempre orientava que os membros de sua comunidade acessassem os cuidados do hospital e do terreiro: "procurassem os médicos do posto de saúde e os mestres Juremeiros, pois uma ciência não vive sem a outra, também sofremos com doenças inventadas pelo homem branco".

A importância de nossa temática se revela nas atuais demandas no campo da saúde, que podem ser verificadas pela emergência contemporânea do interesse da população por serviços que contenham práticas integrativas ${ }^{\mathrm{ix}}$, muitas delas oriundas dos povos originários. A ciência da Jurema Sagrada é repleta de uma complexa trama de saberes. A palavra 'ciência' para juremeiro, significa sabedoria, saber-fazer (episteme) orientado pela voz ancestral da terra, da natureza, dos elementos divinizados que ofertam medicinas de cura.

Portanto, colocamos em análise conceitos importantes da perspectiva da Jurema Sagrada, ancorados no tripé cultura-saúde-espiritualidade. A sabedoria espiritual de matriz indígena aponta um conjunto de artes e ofícios, de confecção de remédios para o corpo físico, mental e espiritual ao mesmo tempo, tal como a yoga para os indianos, reconhecida oficialmente como prática de cura e como patrimônio cultural da humanidade.

ix Para maiores informações, consultar as Práticas Integrativas e Complementares do SUS - Ministério da Saúde. 
Como dissemos anteriormente, a Jurema Sagrada é uma planta enteógena peculiar do sertão de Pernambuco, um arbusto que é cultuado de forma xamânica pelos índios nos interiores do Nordeste e de forma holística nos terreiros de jurema mais próximos ao litoral. A árvore da Jurema ${ }^{\mathrm{x}}$ e seu sumo já foram utilizados na recuperação de pacientes com dependência química na Holanda, como relatam os trabalhos do professor Grunewald ${ }^{10}$. Apontamos a relevância de uma perspectiva transdisciplinar sobre o amplo espectro dessa medicina tradicional, para além de sua composição vegetal, como uma forma de podermos acessar memórias dos modos de conhecimentos ancestrais, na relação saúde-doença e transcendênciadescendência, em sua forma sagrada e artística, respeitando todos os elementos que compõem essa liturgia.

Além da música, da dança e da fumaça, destacamos o chamado 'complexo do mel' associado à jurema indígena, dos cachimbos e maracas (instrumento musical) utilizados na dança ritualística do toré ${ }^{12}$, que se relacionam com a iniciação vegetal, com uma diversidade de ervas que atuam no equilíbrio da relação mente-corpo-espírito, como elementos de sacralização da vida ancorados pelo culto à memória dos ancestrais, dos mortos.

\section{PATRIMÔNIOS CULTURAIS E MEDICINAS TRADICIONAIS}

Os territórios de saber das medicinas dos povos tradicionais, sob a ótica dos ensinamentos da Jurema Sagrada, se inscrevem em modos de saber-fazer, em práticas de cura e cuidados que devem dialogar com as pesquisas no campo das Práticas Integrativas e Complementares em Saúde e também com a Gestão dos Patrimônios Culturais. Esses desafios de convergência de políticas públicas de saúde e cultura junto às medicinas tradicionais indicam a extrema relevância de um sistema de comunicação comunitário, participativo e integrativo.

A medicina tradicional da Jurema Sagrada comporta ao mesmo tempo uma planta suscetível a encaminhamentos de dossiês de patrimonialização, tanto genético (ambiental) como cultural, pois, em torno dessa vegetação, há também os conhecimentos tradicionais associados a ela: na musicalidade, nas formas de expressões artísticas, na culinária, nas festividades populares do Nordeste brasileiro, já reconhecidos como patrimônios culturais pelo Instituto do Patrimônio Histórico e Artístico Nacional (IPHAN), a exemplo do maracatu e do caboclinho.

Ainda no texto Juremologia ${ }^{9}$, podemos entender que o estudo historiográfico da Jurema Sagrada também nos serve de ferramenta para encontramos as primeiras referências documentais ${ }^{10}$ que temos sobre a bebida da jurema, as quais datam do século XVIII. Para o reconhecimento de territórios indígenas, o Serviço de Proteção ao Índio (SPI) requeria a realização de torés por parte dos indígenas como atestado de indianidade. A partir de uma ampla rede comunicativa, muitos grupos indígenas emergentes passaram a aprender com outros grupos ritualísticos, fundados em larga medida no uso da jurema. Se o toré tem uma dimensão pública com ou sem consumo de jurema, é nos rituais mais discretos que essa planta ganha maior centralidade como uma bebida sacramental ou enteógena - termo que se refere ao advento de Deus na pessoa. No entanto, seu modo de preparo e os conhecimentos tradicionais associados a ela são de extrema importância, por isso recomendamos um mapeamento e legitimação do seu uso dentro das

\footnotetext{
x A Jurema [Mimosa tenuiflora (willd.) Poiret.], sinonímia: Mimosa hostilis (Mart.) Benth, M. Nigra J. Huber, M. Cabrera Karsten, ... Antigas Acacia tenuiflora Willd, Acaciahostilys Mart (1), da família Mimosaceae, cujo nomes populares podem ser encontrados em diversas áreas do sertão brasileiro, é uma árvore que floresce no agreste e no sertão nordestino, encontrando-se muito facilmente nas caatingas, onde expande-se muito, dominando quase toda vegetação nas regiões em que se encontra. Situando-a geograficamente, podemos identificá-la no Ceará, Pernambuco, Rio Grande do Norte, sul do Piauí, na Bahia (Vale do São Francisco) e em Alagoas, podendo ainda encontrá-las no México, América Central e no norte da América do Sul, até o Peru. Esta espécie divide espaço com a Algaroba (Família: Mimosaceae. Nome científico: Prosopisjuliflora D.C.), cujos nomes populares são: Alfarroba, Alfarrobeira, Algaróbia, Algarrobo, Goma-de-mesquite. Indicações terapêuticas: adstringente, afrodisíaca e laxativa.), outra espécie de árvore do sertão que absorve quase todo líquido da terra, submetendo outras espécies mais vulneráveis à seca, à morte.
} 
comunidades tradicionais. Encontramos também registros de que o Tribunal do Santo Ofício (a Inquisição) foi extremamente rigoroso com os "rituais gentílicos"10.

Acerca da temática do uso tradicional da Jurema Sagrada e a extrema relevância de ações nas áreas de comunicação e educação patrimonial referentes a esta tradição medicinal, vale destacar que, em decorrência do processo persecutório da Inquisição, muitos desses índios foram, segundo Salles ${ }^{11}$, trazidos do interior, ou seja, do sertão do Nordeste (especialmente da Paraíba e de Pernambuco). Do processo de redistribuição de terras, surgiram as propriedades de Estiva e Acais, em Alhandra, onde surgiu o catimbó-jurema. A localidade é de tal importância no universo mítico relativo ao 'culto da jurema' que veio a ser efetivado, na década passada, um processo de patrimonialização centrado neste lugar, mas que ainda transcorre de forma conflituosa entre comunidades tradicionais, poder público e órgãos de representações religiosas, tais como a Federação Cultural Paraibana de Umbanda, Candomblé e Jurema.

Destacamos que a Jurema Sagrada se expandiu e se difundiu não apenas pelo litoral, mas adentrando também fortemente na Zona da Mata, Agreste e Sertão, além de outras regiões do país. Desde Goiana, na Paraíba, e se estendendo por toda a Zona da Mata pernambucana, a jurema tem densa recorrência e vitalidade, dando proteção (como guardiã sagrada) aos maracatus rurais e também ao de Recife, ao Cavalo Marinho e a outras formas de expressão da cultura popular nordestina. Nos Caboclinhos da Paraíba e de Pernambuco, por exemplo, ocorre a celebração da Caçada do Bode - que 'não existe sem jurema' -, operada no 'calçamento dos caboclos', dos grupos em geral, dos instrumentos musicais e de outros objetos litúrgicos que, sacralizados, ficam protegidos durante o Carnaval.

Abordar o estudo das práticas que tangenciam os eixos de transversalidade da comunicação e da memória medicinal dos povos tradicionais, dos mestres das comunidades de Jurema em suas artes e ofícios, nos leva a considerar os processos de educação em saúde e seus dispositivos de saber-poder, das novas formas biopolíticas ${ }^{12}$ que têm inserido, entre outros, os saberes das rezadeiras e benzedeiras nas chamadas 'medicinas integrativas e tradicionais' no SUS ${ }^{\mathrm{xi}}$.

O estudo da relação medicina e espiritualidade deve tomar o sagrado enquanto conhecimento cultural e não como crença ou curandeirismo, mas dentro de uma proposta de educação patrimonial em saúde na perspectiva de colonial e integrativa, para que possamos cartografar e desenvolver um sistema de comunicação acerca das desdobras da memória da ciência medicinal dos povos tradicionais da Jurema Sagrada como afirmação de um território de saber-fazer fundamental para a história da saúde coletiva no Brasil.

\section{CONSIDERAÇÕES FINAIS}

As análises narrativas dos arquivos de memória da Escola Semente de Jurema demonstram a extrema importância da oferta do acesso dos profissionais de saúde às informações sobre os sistemas medicinais das comunidades tradicionais. Cerca de $80 \%$ dos participantes das atividades são profissionais ou estudantes da área da saúde ou áreas afins, especialmente interessados em processos de formação nas práticas integrativas e complementares em saúde.

Destacamos que o lugar de protagonismo dos mestres e mestras das culturas tradicionais para a construção coletiva dos materiais de comunicação para a educação em saúde é fundamental. As peças e processos de comunicação comunitária em saúde servem de ferramenta fundamental para o registro, preservação e disseminação do território de saberes das medicinas dos povos tradicionais.

xi Para este assunto consultar a referência relacionada: Ministério da Saúde (BR), Secretaria de Atenção à Saúde. Departamento de Atenção Básica. Política Nacional de Práticas Integrativas e Complementares no SUS: PNPIC-SUS [Internet]. Brasília, DF: O Ministério; 2006 [acesso em 2020 jun. 29]. (Série B. Textos Básicos de Saúde). Disponível em: https://bvsms.saude.gov.br/bvs/ publicacoes/pnpic.pdf. 
Processos de comunicação podem servir para a construção de metodologias ressoantes com os inventários participativos de Patrimônios Imateriais da Saúde no Brasil ${ }^{x i i}$, também para subsidiar cursos de formação profissional em saúde no campo das Práticas integrativas e Complementares em Saúde (PICS). Nosso estudo também conclui que a linguagem da arte dos povos tradicionais, especialmente a música, tem a dupla função de comunicar ensinamentos (educação em saúde) e preservar a memória (salvaguarda de patrimônios culturais).

Nas comunidades tradicionais de matriz afro-indígena, não há separação entre medicina, educação, espiritualidade, meio ambiente e saúde, entre tantas outras dicotomias inventadas pelo sistema científico do colonizador. A inserção dos saberes de tradição oral, através de um sistema de comunicação comunitária, no espaço da educação em saúde, significa adentrar as relações de poder acerca das memórias e histórias a serem contadas ou esquecidas, afirmando e comunicando mitologias, símbolos e saberes numa perspectiva contra-hegemônica de uma 'pedagogia colonizada das doenças'.

Ao compartilhar as reflexões postas em curso neste trabalho, esperamos que a construção partilhada e dialógica do conhecimento entre os mestres das medicinas populares seja posta em parceria com os doutores do saber acadêmico. Neste sentido, a Pedagogia Griô é o modelo que indicamos a ser inserido nos campos da educação e comunicação em saúde, promovendo inventários participativos dos patrimônios da saúde, respeitando os territórios do cuidar dos povos indígenas e afro-asiáticos, que nos deixaram seu legado de vastos conhecimentos, inclusive filosóficos, acerca da saúde.

Os pontos aqui tratados são cruciais para entender a escolha da comunidade tradicional de Jurema Sagrada e da Pedagogia Griô como matriz referencial e metodológica para elaborar um plano de comunicação com vistas a incrementar o campo da educação em saúde, no que concerne à formação profissional.

Esse complexo de rituais, saberes e artes de cuidar realizadas dentro da ciência da Jurema Sagrada revelam a importância de desenvolvimento de meios dos registros de memória das comunidades tradicionais e de construção de materiais e processos no campo da comunicação em saúde, para que através da circulação da informação qualificada, a sociedade em geral, os meios acadêmicos e de pesquisa possam reconhecer essa ciência espiritual e medicinal de matriz indígena como um patrimônio cultural da saúde no Brasil.

\section{REFERÊNCIAS}

1. Cavalcanti A. Corredores de hospital: labirintos de brincadeiras e narrações de vida [dissertação]. Niterói: UFF; 2001.

2. Pacheco L, Caíres M. Pedagogia Griô: a reinvenção da roda da vida. Bahia: Minc; 2010.

3. Lifschitz A. Comunidades tradicionais e neocomunidades. Rio de Janeiro: Contra-Capa; 2012.

4. Grunewald R. Jurema e novas religiosidades metropolitanas. Maceió: Edufal; 2008.

5. Araújo I, Cardoso J. Comunicação e saúde. Rio de Janeiro: Editora Fiocruz; 2007.

6. Borges L. Saúde é um estado de completo bem-estar físico, mental e social. Rio de Janeiro: Autosustentável; 2017 jun. 05 [acesso em 2020 jun. 30]. Disponível em: http://autossustentavel. com/2017/06/o-que-e-saude.html.

7. Prandi R. Encantaria brasileira: o livro dos mestres, caboclos e encantados. Rio de Janeiro: Pallas; 2004.

8. Elíade M. O sagrado e o profano: a essência das religiões. São Paulo: Martins Fontes; 2013.

9. Oliveira A. Juremologia: uma busca etnográfica para a sistematização de princípios da cosmovisão da Jurema Sagrada. Pernambuco: UCP; 2017.

10. Grunewald R, Paliot E. Etnografia de salvamento: Hohenthal Jr. no Nordeste do Brasil. Rio de Janeiro: Contra Capa; 2011.

xii Destacamos que não há no Brasil reconhecimentos de patrimônios imateriais da saúde. OS estudos, pesquisas e cursos de gestão de patrimônios em saúde são destinados exclusivamente a patrimônios materiais da saúde. 
Reciis - Rev Eletron Comun Inf Inov Saúde. 2020 jul.-set.;14(3):644-55 | [www.reciis.icict.fiocruz.br] e-ISSN 1981-6278

11. Salles S. À sombra da Jurema: a tradição dos mestres juremeiros na Umbanda de Alhandra. Recife: Editora Universitária UFPE; 2010.

12. Foucault M. Microfísica do poder. Rio de Janeiro: Graal; 1984. 